\title{
Intact stability analysis of dead ship conditions using FORM
}

Choi, Ju Hyuck; Jensen, Jørgen Juncher; Kristensen, Hans Otto Holmegaard; Nielsen, Ulrik Dam; Erichsen, Henrik

Published in:

Journal of Ship Research

Link to article, DOI:

10.5957/JOSR.170005

Publication date:

2017

Document Version

Peer reviewed version

Link back to DTU Orbit

Citation (APA):

Choi, J. H., Jensen, J. J., Kristensen, H. O. H., Nielsen, U. D., \& Erichsen, H. (2017). Intact stability analysis of dead ship conditions using FORM. Journal of Ship Research, 61(3), 167-176.

https://doi.org/10.5957/JOSR.170005

\section{General rights}

Copyright and moral rights for the publications made accessible in the public portal are retained by the authors and/or other copyright owners and it is a condition of accessing publications that users recognise and abide by the legal requirements associated with these rights.

- Users may download and print one copy of any publication from the public portal for the purpose of private study or research.

- You may not further distribute the material or use it for any profit-making activity or commercial gain

- You may freely distribute the URL identifying the publication in the public portal

If you believe that this document breaches copyright please contact us providing details, and we will remove access to the work immediately and investigate your claim 


\title{
Intact stability analysis of dead ship conditions using FORM
}

\author{
Ju-hyuck Choi ${ }^{1}$, Jørgen Juncher Jensen ${ }^{1}$, Hans Otto Kristensen ${ }^{1,2}$, Ulrik Dam Nielsen ${ }^{1,3}$, Henrik \\ Erichsen $^{4}$ \\ ${ }^{1}$ Department of Mechanical Engineering, Technical University of Denmark, ${ }^{2} \mathrm{HOK}$ Marine consult, ${ }^{3}$ Centre for Autonomous \\ Operations and Systems (AMOS), Norwegian University of Science and Technology, ${ }^{4}$ Lloyd's Register EMEA
}

\begin{abstract}
The IMO Weather Criterion has proven to be the governing stability criteria regarding minimum GM for e.g. small ferries and large passenger ships. The formulation of the Weather Criterion is based on some empirical relations derived many years ago for vessels not necessarily representative for current new buildings with large superstructures. Thus it seems reasonable to investigate the possibility of capsizing in beam sea under the joint action of waves and wind using direct time domain simulations. This has already been done in several studies. Here it is combined with the First Order Reliability Method (FORM) to define possible combined critical wave and wind scenarios leading to capsize and corresponding probability of capsize. The FORM results for a fictitious vessel are compared with Monte Carlo simulation and good agreement is found at a much lesser computational effort. Finally, the results for an existing small ferry will be discussed in the light of the current weather criterion.
\end{abstract}

\section{Keywords}

Weather criteria; wind loads; wave loads; FORM; capsize; design load scenarios

\section{Introduction}

Recently the International Maritime Organization (IMO) has initiated a thorough revision of the intact stability rules in the framework of Goal Based Design, e.g. Peters et al. (2013). Several draft guidelines have been issued, e.g. SDC 1/NF.8 by United States and Japan discussing in details the requirements for the hydrodynamic software to be applied including qualitative and quantitative assessment procedures. The focus so far has been mostly on failure modes related to the change of righting lever in waves, notably parametric rolling and pure loss of stability; whereas the dead ship behavior in beam sea still is based on the existing Weather Criterion issued by IMO (1985) as Resolution A.562. This criterion is based to a large extent on model tests of older hull forms and does not provide any probability of capsize for a given vessel, just a pass/no pass result. Furthermore, the wave environment is not explicitly specified in the criterion thus leading to the same requirement whether the ship is sailing in restricted areas or not. A very detailed and precise description of the drawbacks in the IMO Weather Criterion, as applied to modern ships, is given in Bulian and Francescutto (2004). In a recent study by Tompri et al. (2015) a detailed investigation on application of the second generation intact stability criteria has been done. However the criteria for dead ship condition is excluded from this thorough study because the criteria thought to be still in the early phase of development.

The reason for the current revision of the intact stability rules is obvious related to the damage cases reported for ships. Here parametric rolling and pure loss of stability have been in focus for some years, and still loss of containers due to excessive roll motions happens quite often. The dead ship condition in beam sea is not as frequent a scenario. However, the restriction on the transverse metacentric height $(G M)$ imposed by the Weather Criterion can be rather severe and be the governing criterion including damage stability criteria for ships with large superstructures. For instance, this is so for a number of small ferries sailing in Danish water, Erichsen et al. (2015), where the Weather Criterion adds 1 to 2 meters on top of the $G M$ required from all other intact and damage stability criteria. The required increase in GM here leads to rather small roll natural periods with possible discomfort for the passengers and crew. Similar observations are seen for large passenger 
ships, Francescutto et al. (2001). The latter paper also contains an interesting discussion on the assumptions in the Weather Criterion.

Previously, the Weather Criterion has been investigated by e.g. Bulian and Francescutto (2004) using a linearized one degree-of-freedom system. Thereby, the statistics of the roll response is easily obtained. A very detailed description of the wind load including wind admittance factors is given. In another study, Vassalos et al. (2003) use a state-of-the-art six degree-of freedom hydrodynamic software and a time domain analysis is performed. For the example vessel the roll period is chosen such that it is the wave action rather than the wind force that leads to rolling. Estimation of the probability of capsizing is done using Order Statistics, based on the rather limited time domain simulations performed. An interesting conclusion is that the wind and roll scenario up to the onset of capsize is in fair agreement with what is assumed in the Weather Criterion; but also that the probability of the scenario is low, possibly due to the low probability of simultaneously the occurrence of the stipulated wave and wind forces. Other interesting studies along the same lines have been published, e.g. Paroka et al. (2006).

Reliable statistics of capsize in dead ship conditions require long time domain simulations. This can be very time consuming when a detailed hydrodynamic model is applied. Therefore, other statistical procedures than Monte Carlo simulations (MCS) are worth looking at. In the present paper the First Order Reliability Method (FORM) will be considered. It has previously been found useful for extreme value prediction of stationary stochastic time domain processes, e.g. Der Kiureghian (2000), Jensen (2007) and Jensen (2014). Stationary stochastic wave and wind loads can be considered simultaneously, Kogiso and Murotsu (2008), Jensen et al. (2011) and hence readily applicable for an investigation of the Weather Criterion. Kogiso and Murotsu (2008) actually deal with the Weather Criterion using a simplified one degree-offreedom model with a linearized wind load model. They find for an example ship that the capsize probability from the FORM analysis disagree by a factor of 30 from the Monte Carlo simulations. Due to the choice of roll period the main load leading to capsize comes from the wind force. They try to identify the reason for the disagreement and suggest that multiple failure scenarios with the same probability of occurrence are the main reason. It is not clear from their presentation exactly how the statistical predictions from the Monte Carlo simulations are made.

In the present paper a FORM analysis is performed using also a one degree-of-freedom system. Differences compared to the analysis of Kogiso and Murotsu (2008) are the use of more wave and wind components, a non-linear wind load description and a different wave exciting moment.

The aim of the analysis is partly to discuss whether FORM can provide accurate roll angle exceedance probabilities at low probability levels and partly to compare the corresponding scenarios in terms of most probable time domain variations of wave elevation, wind speed and roll angles leading to capsize with those assumed in the IMO Weather Criterion.

The present paper should be seen also in a broader perspective, than in its direct relevance to the IMO Weather Criterion. Thus, the results and analyses will be useful in the steps towards the development of decision support systems providing real-time guidance with respect to navigating vessels in various operational conditions, where the risk of loss of stability is large. Such decision support systems need to be risk-based to account for uncertainties both in the environmental conditions (waves and weather) and in the actual calculations themselves; but, at the same time, the systems must rely on computationally efficient procedures. However, the topics of decision support systems and operational guidance are not addressed specifically in this article but are areas of working progress by the first author as part of an ongoing PhD study.

\section{Mathematical formulation}

The analysis of a dead ship condition in beam sea will be made using a single-degree-of-freedom model adapted from Jensen (2007). Hence, the roll angle $\phi(t)$ as function of time $t$ is determined by the solution of the equation of motion:

$$
\ddot{\phi}=-2 \xi_{1} \omega_{\phi} \dot{\phi}-\xi_{2}|\dot{\phi}| \dot{\phi}-\xi_{3} \frac{\dot{\phi}^{3}}{\omega_{\phi}}-\frac{g G Z(\phi)}{r_{x}^{2}}+\frac{M_{x}}{J_{x}}
$$

where $\xi_{1}, \xi_{2}, \xi_{3}$ are non-dimensional damping coefficients, $g=9.81 \mathrm{~m} / \mathrm{s}^{2}, M_{x}$ the roll exciting moment from wind and waves and $r_{x}$ the roll radius of gyration in water. The roll mass moment of inertia $J_{x}$ is related to the mass of the vessel $\Delta$ through $J_{x}=r_{x}^{2} \Delta$ and the roll natural frequency $\omega_{\phi}=\sqrt{g G M} / r_{x}$, where $G M$ is the still water transverse metacentric 
height. Finally, a super dot means differentiation w.r.t time $t$ and $G Z(\phi)$ is the righting lever as function of the roll angle. In the present study $G Z(\phi)$ is modelled as

$$
G Z(\phi)=\left(G M-A_{1}\right) \sin (\phi)+A_{1} \phi+A_{3} \phi^{3}+A_{5} \phi^{5}
$$

where $A_{1}, A_{3}, A_{5}$ are determined by curve-fitting to the actual $G Z(\phi)$.

The stationary stochastic long-crested wave elevation process $H(t)$ at the position of the vessel is given as

$$
\begin{aligned}
& H(t)=\sum_{i=1}^{m} h_{i}\left(\omega_{i}, t, \theta\right) \\
& h_{i}\left(\omega_{i}, t, \theta\right)=\sqrt{S_{w}\left(\omega_{i}\right) d \omega_{i}}\left(u_{i} \cos \left(\omega_{i} t\right)-\bar{u}_{i} \sin \left(\omega_{i} t\right)\right)
\end{aligned}
$$

where $S_{w}(\omega)$ is the wave spectrum as function of wave frequency $\omega$ and $u_{i}, \bar{u}_{i}$ statistical independent and standard normal distributed variables. The frequency discretization is taken with constant increment $d \omega_{i}=\omega_{i}-\omega_{i-1}$. Secord order and/or short crested waves can easily be included albeit with a significant increase in computational effort, Jensen (2005).

The wave-induced roll exciting moment is assumed linearly dependent on the wave slope:

$$
M_{x, \text { wave }}(t)=\sum_{i=1}^{m} R A O_{\phi}\left(\omega_{i}\right) \sqrt{S_{w}\left(\omega_{i}\right) d \omega_{i}}\left(u_{i} \sin \left(\omega_{i} t\right)+\bar{u}_{i} \cos \left(\omega_{i} t\right)\right)
$$

The response amplitude operator $R A O_{\phi}\left(\omega_{i}\right)$ will in the first part of the paper, dealing with comparison between FORM and MCS analyses, be taken as closed form expressions, Jensen et al. (2004), for a triangular shaped prismatic beam. Later, in the application section, the wave-induced roll moment will be determined by six degree-of-freedom state-of-the-art hydrodynamic software.

The wind-induced roll moment is modelled as

$$
M_{x, \text { wind }}=0.5 \rho_{\text {air }} A_{\text {wind }} C_{\text {wind }}\left(U_{\text {mean }}+U_{\text {gust }}\right)^{2} z_{\text {wind }}
$$

Here $\rho_{\text {air }}, A_{\text {wind }}, C_{\text {wind }}, U_{\text {mean }}, U_{\text {gust }}, z_{\text {wind }}$ are the mass density of air $\left(1.225 \mathrm{~kg} / \mathrm{m}^{3}\right)$, the lateral wind area, the wind coefficient, the mean wind speed, the gust wind speed and, the wind lever, respectively. The gust wind speed is assumed to be a stationary stochastic process:

$$
U_{\text {gust }}(t)=\sum_{j=m+1}^{m+n} \sqrt{S_{\text {wind }}\left(\omega_{j}\right) d \omega_{j}}\left(u_{j} \cos \left(\omega_{j} t\right)-\bar{u}_{j} \sin \left(\omega_{j} t\right)\right)
$$

where $S_{\text {wind }}(\omega)$ is the gust wind spectrum and $u_{j}, \bar{u}_{j}$ again statistical independent and standard normal distributed variables. Several gust wind spectra have been formulated; see e.g. Bec (2010) for a summary. Here the Davenport and the Kaimal spectra have been considered.

For each realization of $\{u, \bar{u}\} \equiv\left\{u_{i}, \bar{u}_{i} ; i=1,2, \ldots, m+n\right\}$ defining the wave and wind scenarios the solution of Eq. (1) yields a time domain response only dependent on the initial conditions. In a stationary stochastic process, the statistics do not depend on the absolute value of time. Hence, if a time $t_{0}$ is chosen sufficiently far away from the initial conditions, the statistical properties of the response will not depend on this value. In the present context $t_{0}$ is chosen as $300 \mathrm{~s}$, since the hydrodynamic memory effect is less than 5-10 times the roll natural period or 150s in typical roll motion simulations, excluding perhaps parametric rolling. The realization, which exceeds a given threshold $\phi_{0}$ at time $t=t_{0}$ with the highest probability, is sought. This can be formulated as a limit state problem, Der Kiureghian (2000), within time-invariant reliability theory:

$$
G\left(\phi_{0},\{u, \bar{u}\}\right)=\phi_{0}-\phi\left(t_{0} \mid\{u, \bar{u}\}\right)=0
$$


Due to the statistical properties of all $u_{i}, \bar{u}_{i}$ the most probable realization of waves and gust wind is the one where

$$
\left|u^{2}\left(\phi_{0}\right)\right| \equiv \sum_{i=1}^{m+n}\left(u_{i}^{2}+\bar{u}_{i}^{2}\right)
$$

has its minimum value. This realization $\left\{u^{*}, \bar{u}^{*}\right\}$ can be considered as a kind of design, or critical wave and wind, scenario leading to exceedance of the prescribed response $\phi_{0}$. Due to the non-linearity in Eq. (1) the limit state surface, Eq. (7), is not linear in $\{u, \bar{u}\}$ and an effective search routine is needed when $m+n$ is large. An excellent summary of optimization algorithms is given by Liu and Der Kiureghian (1991). In the present study two procedures have been implemented: the socalled modified Hasofer-Lind procedure, Liu and Der Kiureghian (1991), and the Hasofer-Lind algorithm supplemented by a circle and line search. Both are based on the original work by Hasofer and Lind (1974). A short outline of the two procedures is given in the Appendix. In the present examples these procedures have provided the design point $\left\{u^{*}, \bar{u}^{*}\right\}$ for all values of the roll limiting angle $\phi_{0}$ up to and even above $G Z\left(\phi_{0}\right)=0$. The procedures seem very versatile and have also proved useful in another study dealing with fatigue damage estimation, Horn and Jensen (2016).

The calculations are most efficiently performed by choosing a moderate value of $\phi_{0}$ and then use the design point for this roll angle as the starting point $\{u, \bar{u}\}$ for the search for the design point for a next higher roll angle. When the design point has been determined the point-wise probability of exceedance, relative to the value $\phi_{0}$, can be estimated by the FORM approximation:

$$
P_{\text {FORM }}\left[\phi \geq \phi_{0}\right]=\Phi\left(-\beta\left(\phi_{0}\right)\right)
$$

where $\Phi$ is the standard normal distribution function and with the reliability index $\beta$ defined as

$$
\beta\left(\phi_{0}\right)=\sqrt{\min \left|u^{2}\left(\phi_{0}\right)\right|}
$$

Mean up-crossing rates can be determined within the FORM approximation from the design point information, Jensen and Capul (2006), and used to estimate the probability of exceedance during a time range $T$. In most cases, the result can be simplified to

$$
P\left[\max _{T} \phi(\mathrm{t})>\phi_{0} \mid \phi_{0}>\phi_{s}\right]=1-\exp \left(-N \exp \left(-0.5 \beta\left(\phi_{0}\right)^{2}\right)\right)
$$

where $N$ is the number of peaks above the mean (close to static) roll angle $\phi_{s}$. The static roll angle $\phi_{s}$ is obtained from Eq. (1) by omitting all dynamic terms and $N$ can be estimated by $N=T \omega_{\phi} / 2 \pi$.

Due to the linearization of the limit state surface around the exact design point the probability information, Eqs. (9) - (11), is not exact, but holds only asymptotically for large values of the reliability index $\beta$. Therefore, Monte Carlo simulations will be performed to validate the FORM results.

The Monte Carlo simulation also uses Eq. (1) and collects for each simulation only the value $\phi\left(t_{0}\right)$, which means that ergodicity has not to be assumed. After $M$ simulations the results are ordered: $\phi_{i} \leq \phi_{i+1}, i=1,2, . ., M$. The point-wise probability of exceedance is then determined as

$$
P_{M C S}\left[\phi \geq \phi_{i}\right]=1-\frac{i-1}{M} ; \quad i=1,2, \ldots, M
$$

with the corresponding reliability index

$$
\beta_{M C S}\left(\phi_{i}\right)=-\Phi^{-1}\left(1-\frac{i-1}{M}\right)
$$


A comparison of the results from Eqs.(10) and (13) can then be used to estimate the accuracy of the FORM approximation. This is done in the next section.

\section{FORM versus Monte Carlo simulations}

This section evaluates the applicability of the FORM approach by considering a fictitious prismatic vessel in dead ship condition, i.e. in beam sea with no forward speed, and using a closed form expression for the wave-induced roll moment, Jensen et al. (2004), for triangular shaped sections. A comparison of this expression with experimental results by Vugts (1968) shows reasonable agreement over the frequency range considered here, albeit generally slightly lower. The moment is taken with respect to a rotational axis in the water plane. This implies a too large moment if the vertical center of gravity is above the water plane due to the coupling to sway, see e.g. Vugts (1968). For the present example the center of gravity is $1.6 \mathrm{~m}$ above the water plane with an assumed $G M=2.5 \mathrm{~m}$ (see later). This change in moment with $G M$ is ignored in this section, where the focus is on statistical methods. Furthermore, $r_{x}=0.4 B$ is assumed where $B$ is the waterline breadth. The parameters in Eqs. (1)-(5) are chosen somewhat arbitrarily as: $\left(\xi_{1}, \xi_{2}, \xi_{3}\right)=(0.012,0.40,0.42)$ (Bulian (2005)), $B=32.2 \mathrm{~m}$, draft $D=10.5 \mathrm{~m},\left(A_{1}, A_{3}, A_{5}\right)=(5,1,-10) \mathrm{m}$, block coefficient $=0.61, C_{\text {wind }}=1, A_{\text {wind }}=4 L D, U_{\text {mean }}=26 \mathrm{~m} / \mathrm{s}$. The ship length $L$ cancels out for a prismatic beam. The assumed wind area is quite large, somewhat between what is seen for container vessels and large cruise ships. The wind lever is taken as

$$
z_{\text {wind }}(\phi)=0.5 D\left(1+\frac{A_{\text {wind }}}{L D}\right)\left(0.3+0.7 \cos ^{2} \phi\right)
$$

where the variation of the lever with roll angle is taken from Vassalos et al. (2003). With these values the static roll angle due the mean wind speed $\phi_{s}=4.9 \mathrm{deg}$.

The waves are modelled by a JONSWAP spectrum with significant wave height $H_{s}=11 \mathrm{~m}$ and zero up-crossing period $T_{z}=12 \mathrm{~s}$. The gust wind spectrum is of the Davenport type with a variance equal to $6 K U_{\text {mean }}^{2}$, where $K=0.003$. Also the Kaimal spectrum with the same variance as the Davenport at $U_{\text {mean }}=26 \mathrm{~m} / \mathrm{s}$ has been applied, but even if the frequency variation of the two spectra is different, especially at low frequencies, the results regarding exceedance probabilities are quite similar for the present example. The frequency range for the wave spectrum is taken as $\left[\pi / T_{z}, 3 \pi / T_{z}\right]$ whereas for the gust wind speed the frequency range used is $\left[0.05 \mathrm{~s}^{-1}, 0.60 \mathrm{~s}^{-1}\right]$.

Different numbers of wave and wind components have been considered to investigate the sensitivity to this choice, Jensen et al. (2016), but only minor differences have been found, given a total number of $m+n=50$. In the present example $m=30$ and $n=20$ are used. The resulting wave height and wind speed spectra are shown in Fig. 1.

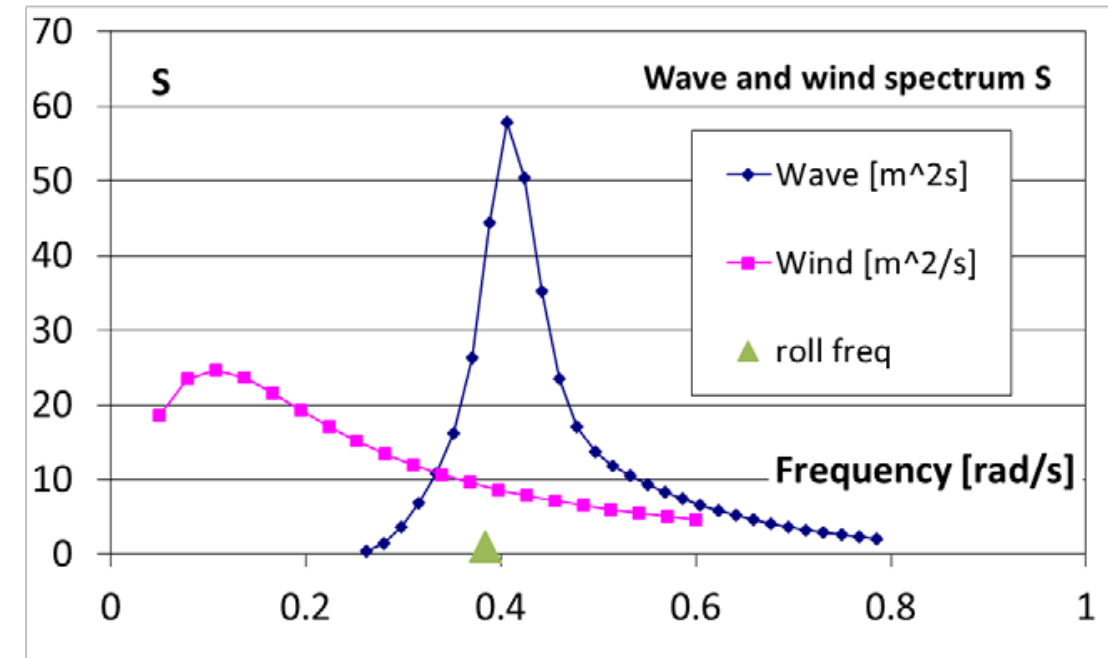

Fig. 1. JONSWAP wave height and Davenport wind speed spectra applied. Discretization $m=30, n=20$ 
The time $t_{0}=300 \mathrm{~s}$ is found large enough to avoid notable influence from the initial condition and short enough to avoid repetition of the stochastic wave and wind loads with the current discretization; see also Nielsen and Jensen (2009). The time step in the Runge-Kutta solution procedure of Eq. (1) is taken as $0.5 \mathrm{~s}$.

With the given set of parameters used for the present fictitious vessel the IMO Weather Criterion, IMO (1985), prescribes a minimum $G M=2.5 \mathrm{~m}$ and this value is assumed for the present study. The corresponding $G Z$ curve is derived from Eq. (2) and shown in Fig. 2. The roll natural frequency $\omega_{\phi}$ becomes $0.38 \mathrm{rad} / \mathrm{s}$ implying that the wave-induced roll excitation dominates over the wind- induced roll excitation, see Fig. 1. Results for other $G M$ values can be found in Jensen et al. (2016).

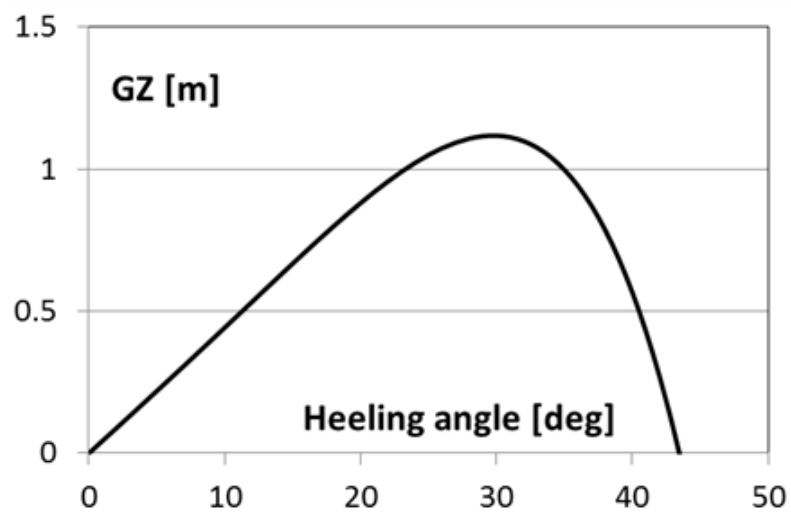

Fig. 2. $G Z$ curve for $G M=2.5 \mathrm{~m}$

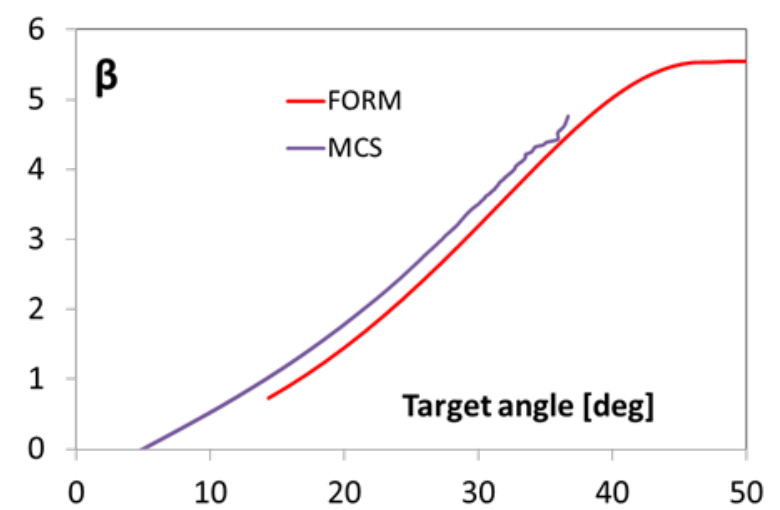

Fig. 3. Reliability Index $\beta$ as function of target angle $\phi_{0}$. FORM and MCS $\left(10^{6}\right.$ simulations $)$

A comparison between the reliability index obtained from FORM and Monte Carlo simulations (MCS) is given in Fig. 3. The MCS are performed with 1,000,000 simulations implying a maximum reliability index $\beta_{\text {MCS }}=-\Phi^{-1}\left(10^{-6}\right)=4.75$. The Coefficient of Variation (COV) of the MCS is roughly equal to $1 / \sqrt{E}$ where $E$ is the number of results above the target value. Thus, with a prescribed COV of, say, 0.1 , the number $E=100$ which means that MCS is only accurate here up to $\beta_{\text {MCS }}=-\Phi^{-1}\left(10^{-4}\right)=3.72$. This is in agreement with a visual inspection of Fig. 3, where the MCS results start to fluctuate about this value. As comparison each point on the FORM curve only requires around 600 calls to the time domain code, using the Hasofer-Lind procedure with circle and line search, and thus if only the results for a few large target roll angles are needed then FORM is much more computational effective than MCS. Each call to the time domain FORTRAN code takes about $0.01 \mathrm{~s}$ in CPU time on a standard PC.

If the reliability index is needed for the whole range of roll angles then the most accurate means is to run MCS for the 
lowest roll angles, where MCS is accurate, and FORM for the largest roll angles, where FORM becomes asymptotically correct, and then interpolate between these values, see e.g. Jensen (2014).

For a linear system $\beta=\left(\phi_{0}-\phi_{s}\right) / s_{\phi}$ where $s_{\phi}$ is the standard deviation of the roll angle, e.g. Jensen and Capul (2006). It is seen from Fig. 3 that the non-linearity in Eq. (1) influences $\beta$ to some extent. For the MCS results $\beta=0$ corresponds to $\phi_{0}=\phi_{s}$.

Generally, the FORM results are seen to be slightly conservative compared to the MCS results for lower values of the reliability index $\beta$. However, when $\beta$ exceeds about 4 the FORM results seem to approach the MCS results, albeit the MCS results here are scarce even with 1,000,000 simulations. When the target roll angle approaches the angle of vanishing stability ( $\mathrm{GZ}=0, \phi_{0}=43.5 \mathrm{deg}$ ) the reliability index $\beta$ tends to a constant value as expected as the ship then capsizes.

A use of a Second Order Reliability Method (SORM) could possibly reduce the difference to the MCS results as it takes into account the curvature of the limit state function, Eq. (7), around the design point, see e.g. Der Kiureghian (2000), but has not be considered here where the focus is on extreme roll angles.

\section{Critical wave and wind scenarios}

For the present fictitious vessel the IMO Weather Criterion, IMO (1985), prescribes a minimum $G M=2.5 \mathrm{~m}$ as mentioned before. Hence it is found interesting to compare the deterministic critical roll scenario postulated in IMO (1985) with the critical wave and wind scenario obtained from the FORM analysis for this GM value. The set of FORM results is found by substituting the design point value $\left\{u^{*}, \bar{u}^{*}\right\}$ into Eqs. (3) and (6). These wave and wind design scenarios are shown in Figs. 4 and 5 with the corresponding critical roll variation in Fig. 6 . The target roll angle is taken as $\phi_{0}=37 \mathrm{deg}(0.65 \mathrm{rad})$ as a realistic down flooding angle.

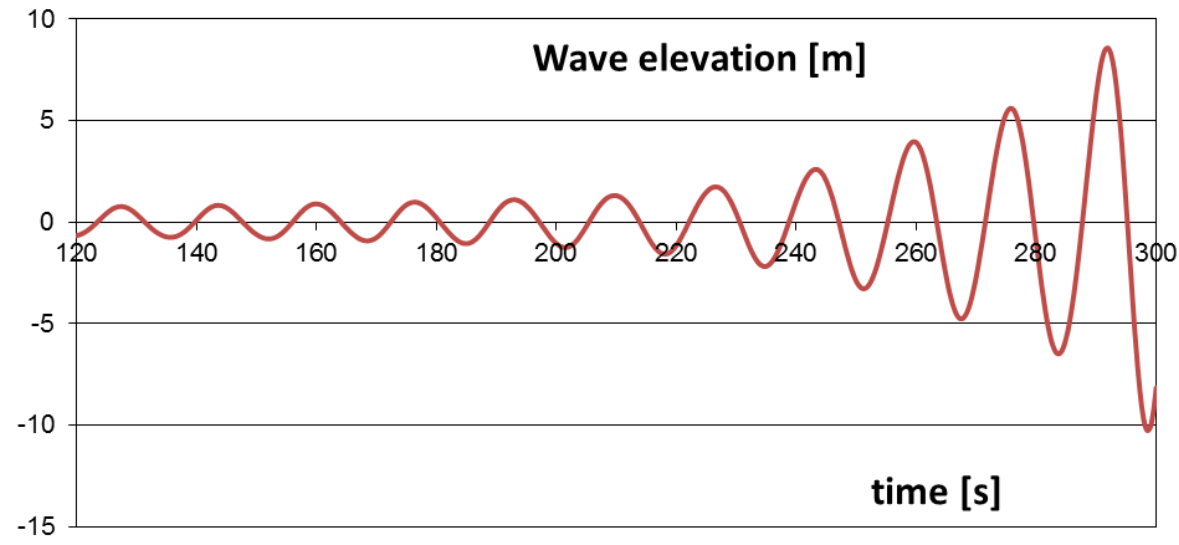

Fig. 4. Most probable wave elevation scenario at the position of the ship leading to a roll angle of $37 \mathrm{deg}$ for $G M=2.5 \mathrm{~m}$

The first 120s of the time signals are not shown as they are influenced by the choice of initial conditions. The remaining parts, shown in Figs. 4-6, are unaffected by the initial conditions. It can be observed from Fig. 6 that the ship attains a roll angle of 22.6deg to windward as measured from the static wind heel position one roll period prior to 'capsize', which is very close to the similar angle (denoted $\varphi_{1}$ ) in IMO (1985): $22.7 \mathrm{deg}$. In addition, the maximum wind speed $(30.7 \mathrm{~m} / \mathrm{s}$ from Fig. 5) is close to the assumed maximum wind speed in IMO (1985): $\sqrt{1.5} U_{\text {mean }}=31.8 \mathrm{~m} / \mathrm{s}$. The maximum roll angle occurs, as expected, when the wave slope is large at the position of the ship after the passing of a wave trough, see Fig. 4 and 6.

An application of these critical wave and wind scenarios are to use them subsequently in a more accurate 6D deterministic 
hydrodynamic analysis. Then the resulting roll motion can be compared to Fig. 6 and if reasonable overall agreement is found, the new maximum roll angle can be associated with the same reliability index. This is a so-called Model Correction Factor Approach, Ditlevsen and Arnbjerg (1994). For detailed applications to stationary processes including some improvements, see e.g. Alibrandi and Der Kiureghian (2012) and Seng and Jensen (2013).

In Fig. 4, it is seen that the most probable wave episode, leading to exceedance of 37 deg has a nearly constant period close to the roll natural period of $16 \mathrm{~s}$, even if the zero-crossing period of the sea state is $12 \mathrm{~s}$. This reflects the resonance behavior of the roll response and the ability of the FORM procedure to identify this critical, and most probable, wave scenario leading to capsize.

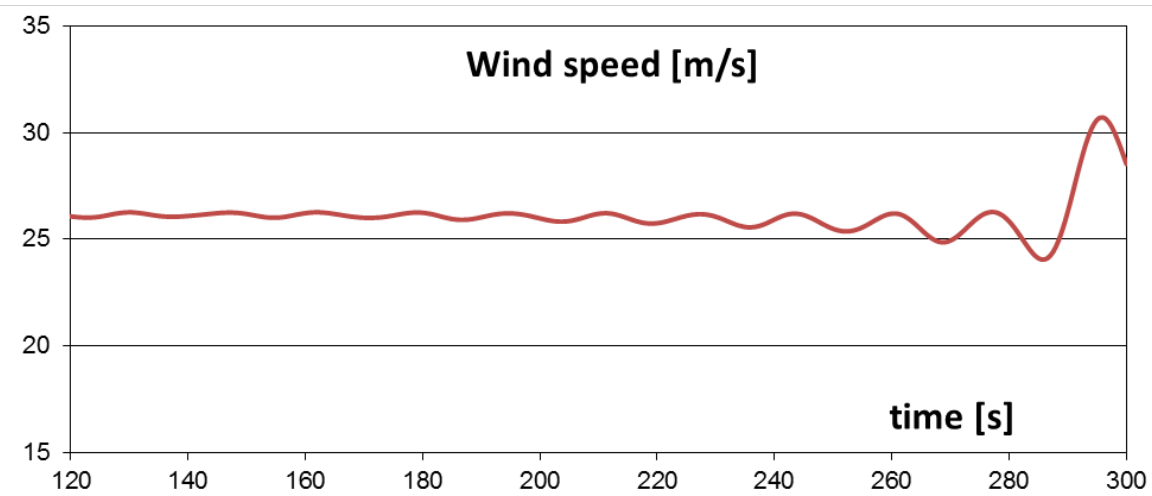

Fig. 5. Most probable wind speed scenario leading to a roll angle of $37 \mathrm{deg}$ for $G M=2.5 \mathrm{~m}$

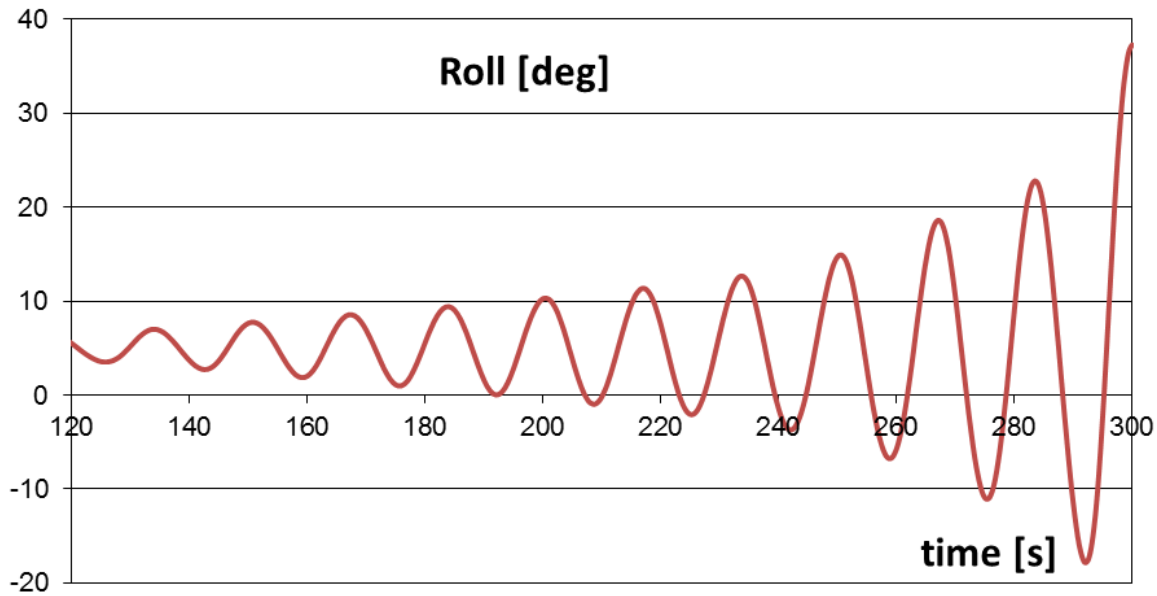

Fig. 6. Most probable roll angle scenario leading to a roll angle of $37 \mathrm{deg}$ for $G M=2.5 \mathrm{~m}$

The reliability index for this roll exceedance scenario is $\beta=4.58$ and the corresponding probability of exceedance during 3 hours of operation becomes 0.02 by Eq. (11). This value might be a reasonable number in this severe sea state, given the rare situation of a dead ship condition. It is noted that the probability depends significantly on the roll angle defining ‘capsize' as e.g. a limiting angle of $40 \mathrm{deg}(\beta=5.03)$ implies an order of magnitude lower probability than for 37deg.

Generally, the analysis of this fictitious vessel yields confidence in the calculation procedures and therefore, in the next section, a real-world vessel will be considered and compared with the regulations by IMO (1985). 


\section{Application example}

The example deals with a small ferry designed for inland transportation in Danish waters. The pertinent data are presented in Table 1. Two different GM values are considered with and without accounting for IMO weather criteria. The large influence of the weather criterion on the required GM has been observed before for small ferries, Erichsen et al (2015), and makes it interesting to quantify the probability of capsize inherent in this regulation. It is assumed that the same metacentric height $K M$ is used for both cases, meaning that the different values of $K G$ are used whereas the draft and displacement are the same.

Table 1 Principal particulars

\begin{tabular}{|c|c|c|c|}
\hline \multicolumn{2}{|l|}{ Item } & $\begin{array}{c}\text { w/o weather } \\
\text { criteria }\end{array}$ & $\begin{array}{l}\text { w/ weather } \\
\text { criteria }\end{array}$ \\
\hline Length & $L[\mathrm{~m}]$ & \multicolumn{2}{|c|}{45.0} \\
\hline Breadth & $B[\mathrm{~m}]$ & \multicolumn{2}{|c|}{13.1} \\
\hline Draft & $D[\mathrm{~m}]$ & \multicolumn{2}{|c|}{2.7} \\
\hline Wind area & $A_{\text {wind }}\left[\mathrm{m}^{2}\right]$ & \multicolumn{2}{|c|}{501.7} \\
\hline Wind lever & $Z_{\text {wind }}[\mathrm{m}]$ & \multicolumn{2}{|c|}{6.961} \\
\hline Metacentric height & $G M[\mathrm{~m}]$ & 2.285 & 4.072 \\
\hline Vertical center of gravity & $K G[\mathrm{~m}]$ & 5.965 & 4.178 \\
\hline Roll natural frequency & $\omega_{\phi}[\mathrm{rad} / \mathrm{s}]$ & 0.80 & 1.05 \\
\hline Roll radius of gyration & $r_{x}[\mathrm{~m}]$ & $0.4532 B$ & $0.4606 B$ \\
\hline
\end{tabular}

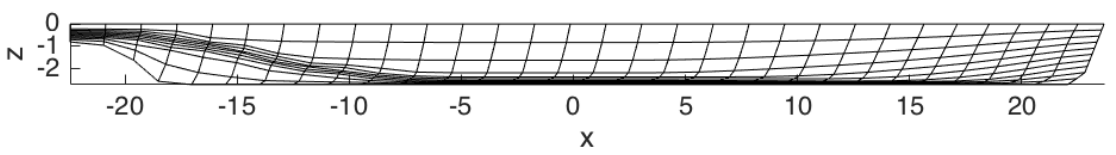

Fig. 7. 3D panel model for the ferry

The roll exciting moment (Froude-Krylov and diffraction) is calculated for the actual hull by using the 3D hydrodynamic WAMIT® procedure (wamit.com), Fig. 7. The moment is taken with respect to the center of gravity. The roll radius of gyration, $r_{x}$ is adjusted so that the roll natural frequency equal to the result from WAMIT. Fig. 8 shows the calculated RAO of the roll moment for different loadings. The $G Z$ curves are calculated by using Eq. (2)and relevant coefficients are found from the loading manual. Fig. 9 shows the two $G Z$ curves. For the both cases the same damping coefficients $\xi_{1}, \xi_{2}, \xi_{3}$ are used as before, and it might be good enough for the purpose of relative comparison between different $G M$ cases. The radiation force as well as the roll exciting moment were also calculated for a finite water depth of $20 \mathrm{~m}$ which is realistic in Danish waters and compared with the case with infinite depth of water. However, the difference is small as the water depth to draft ratio is still large. 


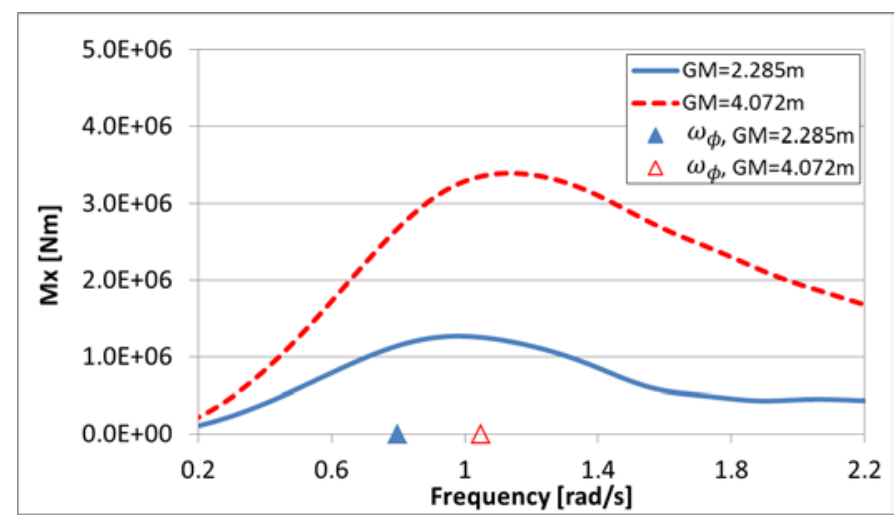

Fig. 8. RAOs of wave excitation moments for the ferry

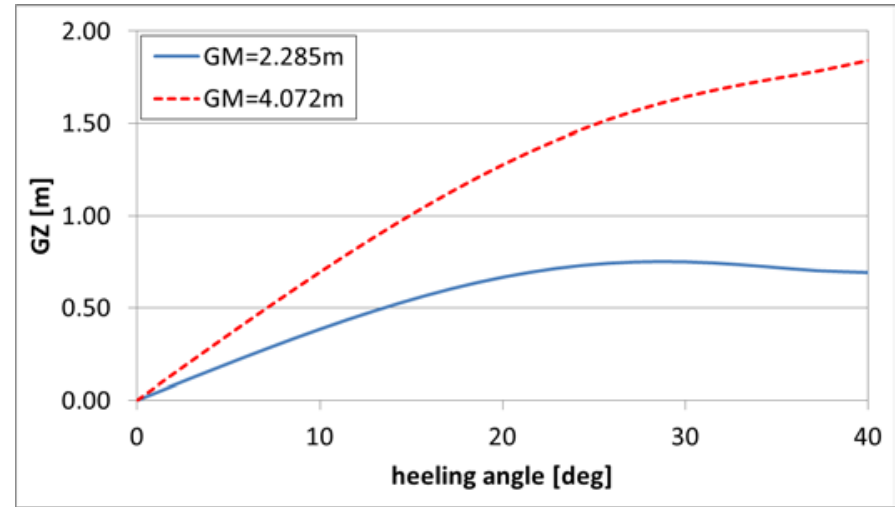

Fig. 9. GZ curves for different $G M$

The stationary wave condition is specified as a JONSWAP spectrum with significant wave height $H_{s}=3.5 \mathrm{~m}$ and zero upcrossing period $T_{z}=5 \mathrm{~s}$ as often assumed a realistic extreme condition in Danish waters. The wind spectrum is the same Davenport spectrum as used in the previous example. A total number of 50 wave elevation and wind speed components $(\mathrm{m}$ $=30$ and $n=20$ ) is used. The spectra and the roll natural periods are shown in Fig. 10, and it is seen that the waves are more important factor for roll excitation for both cases.

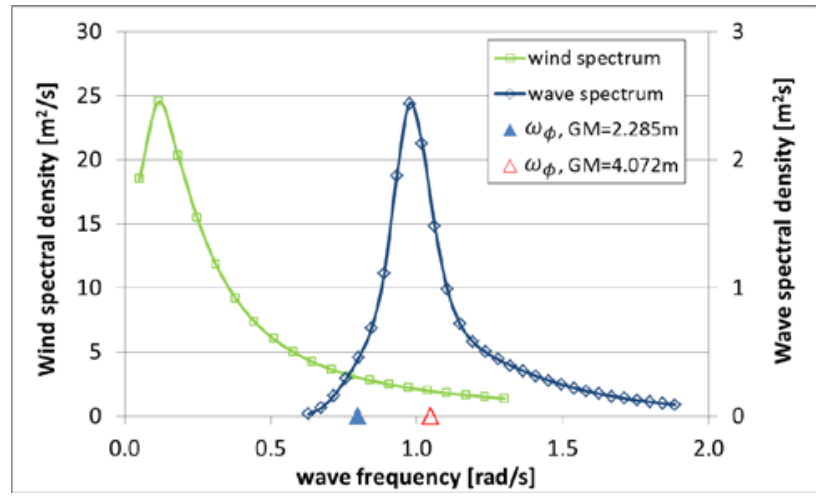

Fig. 10. JONSWAP wave height spectrum and Davenport wind speed spectra applied for the ferry 
From the FORM analysis, the reliability index $\beta$ as function of target roll angle is shown in Fig. 11. The target (limiting) roll angle for the ferry is $34.5 \mathrm{deg}$ due to down-flooding points and thus for the case with $G M=2.285 \mathrm{~m}$ the probability of exceedance during 3 hours becomes $5 \times 10^{-6}$, i.e. the return period for the exceedance of 34.5deg is roughly 70 years in this severe sea state. With $G M=4.072 \mathrm{~m}$ as required from the IMO weather criterion the probability of exceedance relative to roll angles less than 40deg becomes nearly one meaning that the case with $G M=4.072 \mathrm{~m}$ from IMO weather criterion is more dangerous relative to than the case with $G M=2.285 \mathrm{~m}$. This result is completely opposite to the previous work with the same vessel and environmental condition by Jensen et al. (2016), where the wave exciting moments are assumed to be the same for the different loadings.

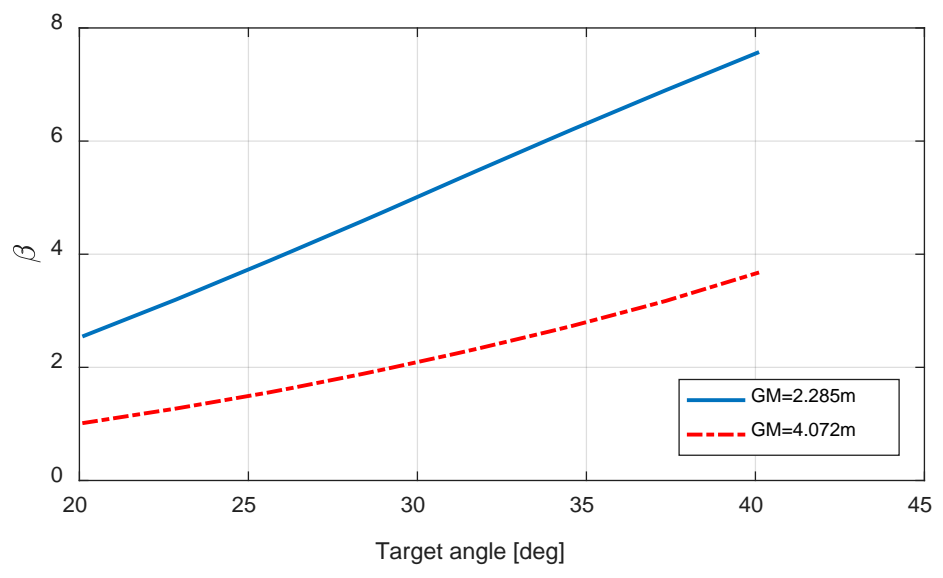

Fig. 11. Reliability Index $\beta$ as function of target roll angle $\phi_{0}$.

The reason for this unexpected result - $\beta$ is the largest for $G M=2.285 \mathrm{~m}$ - can be clearly explained from the Fig. 12 which presents the random variables $\left\{u^{*}, \bar{u}^{*}\right\}$ at the design point and corresponding critical waves and wind scenarios in Figs. 1314. It can be seen that waves and wind both contribute to the external moment in the case with $G M=2.285 \mathrm{~m}$ whereas the wind forces are negligible for $G M=4.072 \mathrm{~m}$. The reason for this is that the roll natural frequency for $G M=4.072 \mathrm{~m}$ is farther away from the wind spectrum than for $G M=2.285 \mathrm{~m}$, see Fig. 10 . Moreover, in the case with $G M=4.072 \mathrm{~m}$, the wave elevations are smaller compared with $G M=2.285 \mathrm{~m}$, meaning that relatively smaller waves are needed to reach a target roll angle in the case with $G M=4.072 \mathrm{~m}$ due to the larger RAO of wave exciting moment (Fig. 8).

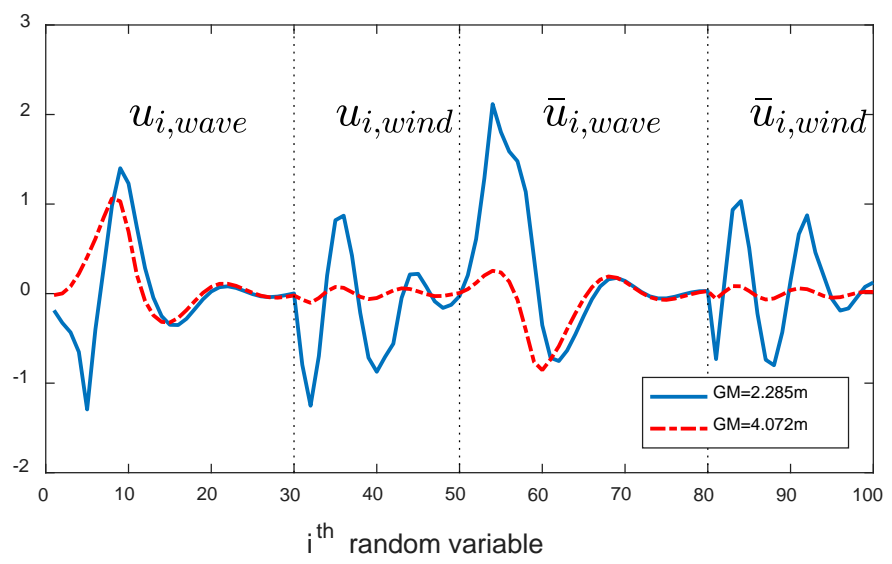

Fig. 12. $u_{i}, \bar{u}_{i}$ for the critical wave episodes 
The variation of the reliability index $\beta$ over $G M$ to the prescribed stationary wave and wind systems is investigated. To check the sensitivity three different zero upcrossing periods are considered. The corresponding wave excitations and $G Z$ curves are presented in Figs. 16 and 17. As shown in Fig. 18 the reliability index $\beta$ is not a monotonic increasing function of $G M$, but has a minimum value around $G M=4.5-5.0 \mathrm{~m}$ meaning the probability of exceeding a specified roll angle here is the maximum. This means that the minimum GM-requirement by IMO weather criterion doesn't hold in the present calculation and supports the conclusion by e.g. Bulian and Francescutto (2011) and IMO (2017) document that a GM limit curve cannot be derived, but rather only ranges of allowable $G M$ values. To get the allowable ranges of $G M$ at the design stage, the actual ship parameters for various loadings as well as the adequate model of roll exciting moment by waves and wind should be taken into account considering realistic operational conditions.

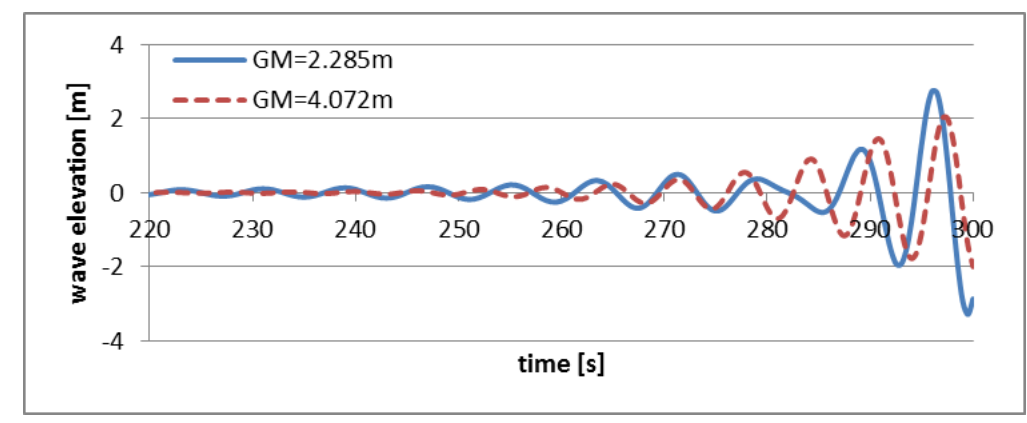

Fig. 13. Comparison of the most probable wave scenario leading to a roll angle of $34.5 \mathrm{deg}$ for different $G M$ values

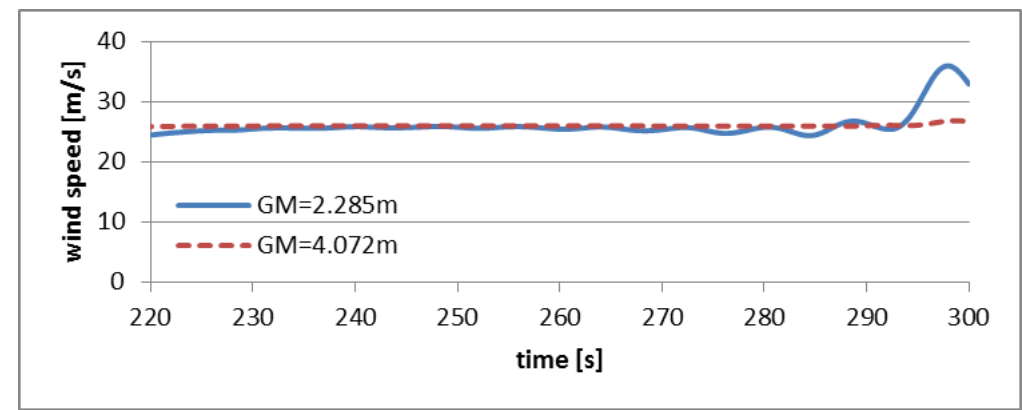

Fig. 14. Comparison of the most probable wind scenario leading to a roll angle of $34.5 \mathrm{deg}$ for different $G M$ values

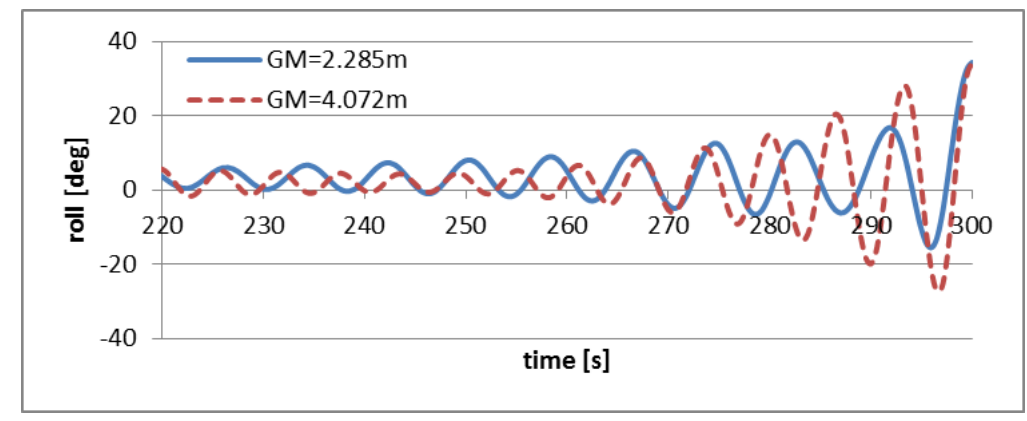

Fig. 15. Comparison of the most probable roll angle scenario leading to a roll angle of $34.5 \mathrm{deg}$ for different $G M$ values 


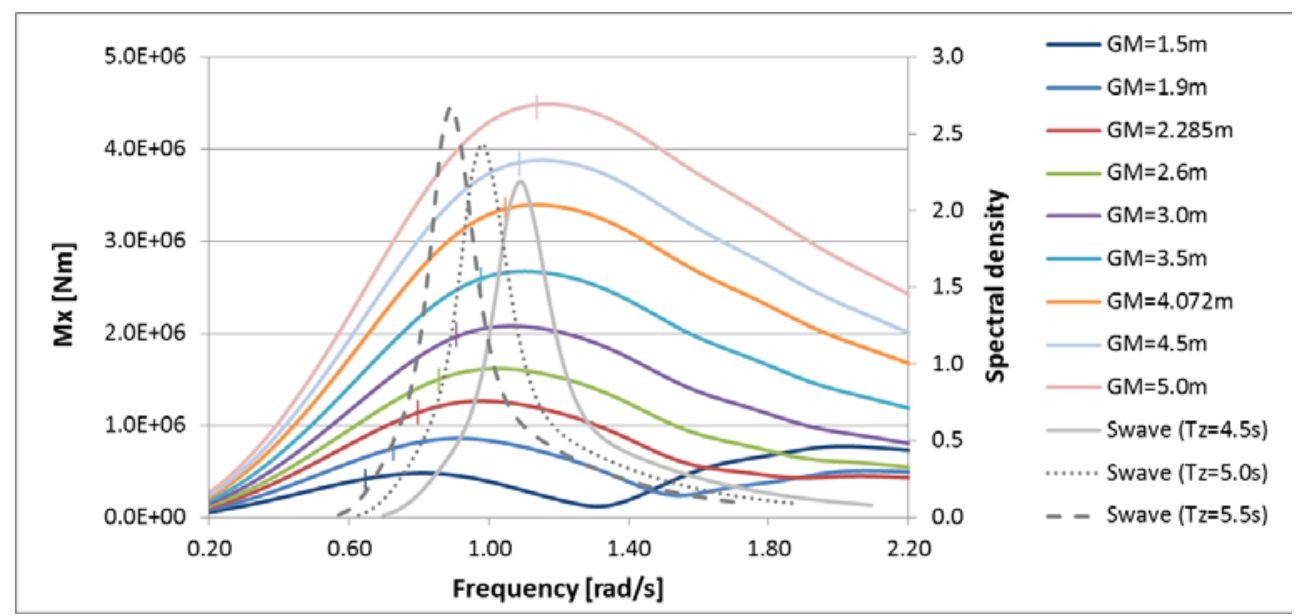

Fig. 16. RAOs of wave excitation moments for different values of $G M$ (vertical symbols denote the roll resonance frequencies)

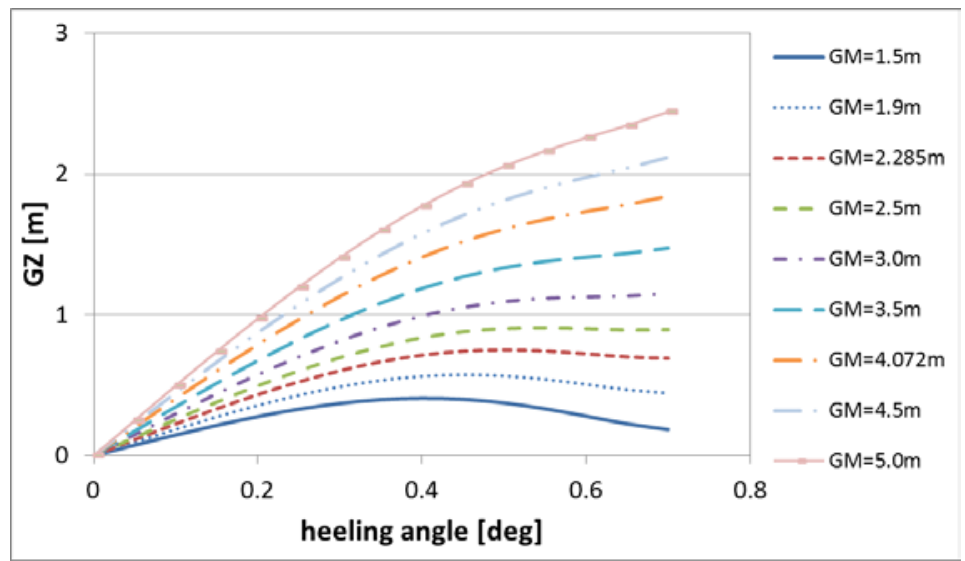

Fig. 17. $G Z$ curves for different values of $G M$

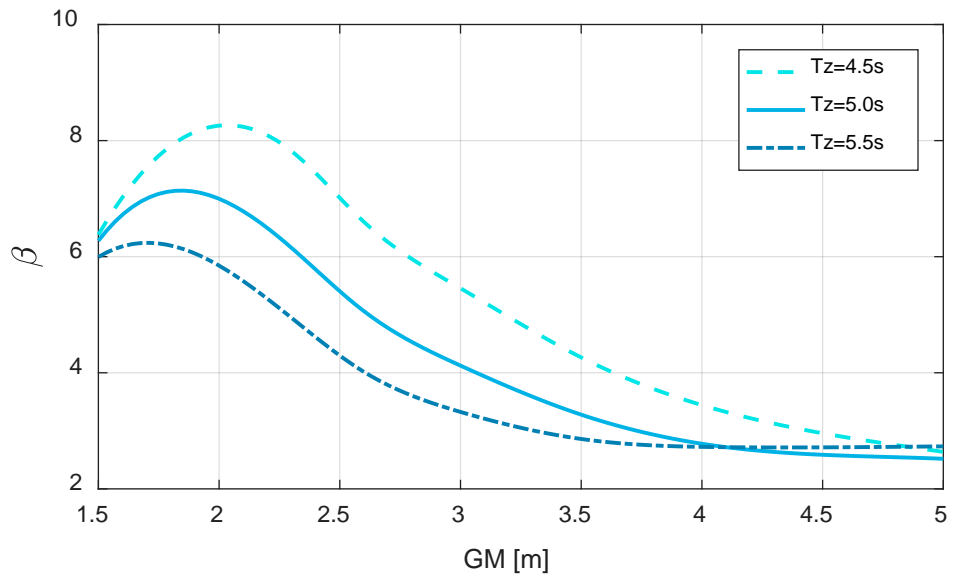

Fig. 18. Reliability index $\beta$ as function of $G M$ for the target angles $\phi_{0}=34.5 \mathrm{deg}$ 


\section{Conclusions}

The paper addresses the search for second generation of intact stability criteria for ships in dead ship conditions subjected to stochastic wave and wind forces.

The physical model for the roll motion is a standard 1D model, but the paper suggests a new application of the FORM procedure for estimation of the extreme value distribution of the roll angle up to capsize.

The results indicate that the FORM procedure is a feasible tool for extreme value prediction of the roll motion and also shows that a standard GM limit curve cannot be constructed in line with current research results regarding the formulation of Second Generation Intact Stability Rules. Also, the lack of an accepted target probability of failure makes a quantitative evaluation impossible. Further studies considering more vessels, operational conditions and a coupling between ship motions components are obviously needed together with an IMO specification of the allowable probability of failure.

In the existing Weather Criterion issued by IMO (1985) there is indirectly a predefined relation between the wind speed and the associated wave action. The wind speed is assumed to be $26 \mathrm{~m} / \mathrm{s}$ and the associated wave action is given by the formula for the angle of roll. According to the present rule formulation the Weather Criterion can be modified, as the wind speed of $26 \mathrm{~m} / \mathrm{s}$ can be reduced for ships operating in restricted services, but the coupling to the wave action through the formula for the roll angle is too stringent - this should also be modified if the waves are not so severe for a given area i.e. in restricted services. The relation between wind speed and associated waves should be evaluated separately, such that the expected external conditions (wind and wave loads) are taken into account individually by a risk based decision support system, where the risk assessment is carried out by using a calculation procedure as described in this paper.

\section{References}

Alibrandi, U and Der Kiureghian, A (2012). "A gradient-free method for determining the design point in nonlinear stochastic dynamic analysis”, Probabilistic Engineering Mechanics, Vol 28, pp 2-10

Bec, J (2010). "Influence of wind spectrum formula choice on footbridge response". $5^{\text {th }}$ Int Symp Computational Wind Eng, Chapel Hill, North Carolina, USA, May 23-27

Bulian, G and Francescutto, A (2004). "A simplified modular approach for the prediction of the roll motion due to combined action of wind and waves". J. Engineering for the Maritime Environment, Vol 218, pp 189-212

Bulian G (2005) . "Nonlinear parametric rolling in regular waves-a general procedure for the analytical approximation of the GZ curve and its use in time domain simulations”. Ocean Eng, Vol 32, pp 309-330

Bulian, G and Francescutto, A (2011). "Considerations on Parametric Roll and Dead Ship Conditions for the Development of Second Generation Intact Stability Criteria”, Proc. $12^{\text {th }}$ International Ship Stability Workshop, 12-15 June 2011, Washington, D.C. USA.

Der Kiureghian, A (2000). "The geometry of Random Vibrations and Solutions by FORM and SORM". Probabilistic Engineering Mechanics, Vol 15, pp 81-90

Ditlevsen, O and Arnbjerg-Nielsen, T (1994). "Model-Correction-Factor Method in Structural Reliability”. Journal of Engineering, Vol. 120, pp 1-10.

Erichsen, H, Kristensen, HO, Jensen, JJ and Tvedt, EI (2015). “Small Ro/Pax Vessel Stability Study”. Proc. 2015 World Maritime Technology Conference, Providence, Rhode Island, USA

Francescutto, A., Serra, A. and Scarpa, S. (2001). "A critical analysis of weather criterion for intact stability of large passenger vessels”. Proc. OMAE'01, June 3-8, 2001, Rio de Janeiro, Brazil, pp 829-836

Hasofer, AM and Lind, NC (1974). "Exact and invariant second .moment code format”. J. Eng Mech, Vol 100, pp111-121

Horn, J-T and Jensen, JJ (2016). "Reducing uncertainty of Monte Carlo estimated fatigue damage in offshore wind turbines using FORM”, Proc $13^{\text {th }}$ PRADS conference, September 4-8, 2016, Copenhagen, Denmark

IMO (1985). "Recommendations on a Severe Wind and Rolling Criterion for the Intact Stability of Passenger and Cargo Ships of 24 meters in Length and Over”. Resolution A.562, International Maritime Organization.

IMO (2017),“FINALIZATION OF SECOND GENERATION INTACT STABILITY CRITERIA -Danish Sample Ship Calculation 2016”, SUB-COMMITTEE ON SHIP DESIGN AND CONSTRUCTION, 4th session, Agenda item 5, SDC 4/INF.XX, http://www.skibstekniskselskab.dk/s/Sample-Calculation-Results-Intact-Stability.pdf

Jensen, JJ, Mansour, AE and Olsen, AS (2004). “ Estimation of ship motions using closed-form expressions”. Ocean Engineering, Vol 31, No.1, pp 61-85 
Jensen, JJ (2005), “Conditional Second Order Short-crested Water Waves Applied to Extreme Wave Episodes”, J. Fluid Mechanics, Vol. 545, pp 29-40

Jensen JJ and Capul J (2006). "Extreme Response Predictions for Jack-up Units in Second Order Stochastic Waves by FORM”. Probabilistic Engineering Mechanics, Vol 21, pp 330-337

Jensen, JJ (2007). "Efficient estimation of extreme non-linear roll motions using the first-order reliability method (FORM)". J. Marine Science and technology Vol 12 No. 4 pp 191-202

Jensen, JJ, Olsen, AS and Mansour, AE (2011). “Extreme wave and wind response predictions”. Ocean Engineering, Vol 38 No. 17-18, pp 2244-2253

Jensen JJ (2014). “Conditional stochastic processes applied to wave load predictions”. Weinblum Memorial Lecture, J. Ship Research, Vol 59, No. 1, pp. 1-10

Jensen, JJ, Choi, J-h., Kristensen, HO, Nielsen, UD, Erichsen, H, Tvedt, EI (2016). “An attempt to define critical wave and wind scenarios leading to capsize in beam sea”, Proc $13^{\text {th }}$ PRADS conference, September 4-8, 2016, Copenhagen, Denmark

Kogiso, N and Murotsu, Y (2008). “Application of First Order Reliability Method to ship stability - Final report from Scape Committee (Part 5)”. Proc $6^{\text {th }}$ Osaka Coll. On Seakeeping and Stability of Ships, Vol B, pp 266-273

Liu, P-L and Der Kiureghian, A (1991).”Optimization algorithms for structural safety”. Structural Safety, Vol 9, pp 161-177

Nielsen, U.D. and Jensen, J.J. (2009). ”Numerical Simulations of the Rolling of a Ship in a Stochastic Sea - Evaluations by use of MCS and FORM". Proc. $28^{\text {th }}$ OMAE, Honolulu, HI, USA.

Peters, WS, Belenky, B and Spyrou, K (2013). "On Alignment of the Second Generation IMO Intact Stability Criteria with the Goal Based Standards: Evaluation of the Safety Level”. Proc $13^{\text {th }}$ Int. Ship Stability Workshop, Brest, France, 23-26 September

Paroka, D, Ohkuwa, Y and Umeda, N. (2006), “Capsizing Probability Prediction for a Large Passenger Ship in Irregular Beam Wind and Waves: Comparison of Analytical and Numerical Methods”. Journal of Ship Research, Vol 50, No. 4, pp 371-377

Seng, S and Jensen, JJ (2013). "An Application of a Free Surface CFD method in the Short-Term Extreme Response Analysis of Ships”, Proceedings PRADS’2013, 20-25 October 2013, CECO, Changwon City, Korea

Tompuri, M, Ruponen, P, Forss M, Lindroth, D (2015). “Application of the Second Generation Intact Stability Criteria in Initial Ship Design”, Transactions - Society of Naval Architects and Marine Engineers, Vol 122, pp 20-45

Vassalos, D, Jasionowski, A and Cichowicz, J (2003). "Weather Criterion - Questions and answers", Proc $8^{\text {th }}$ Int Conf on Stability of Ships and Ocean Vehicles, Portugal, pp 695-707

Vugts, JK (1968). "The hydrodynamic coefficients for swaying, heaving and rolling cylinders in a free surface, Int. Shipbuilding Progress, Vol 15, Issue 167, pp 251-276

\section{Appendix}

Two optimization algorithms have been implemented in the present study:

- $\quad$ Modified Hasofer-Lind method (M-HL), Liu and Der Kiureghian (1991)

- An extension of the Hasofer-Lind method with circle and line steps (HL-CL)

Fig. 18 shows the basic principle of the search for the design point $\underline{u}^{*}$. The iteration steps in these procedures are outlined below.

Hasofer-Lind (HL)

Based on the previous iteration step $\underline{u}_{k}$ the new iteration point $\underline{u}_{k+1}$ is determined as

$$
\underline{u}_{k+1}=\underline{a}_{k}=\left[\nabla G\left(\underline{u}_{k}\right) \underline{u}_{k}-G\left(\underline{u}_{k}\right)\right] \frac{\nabla G\left(\underline{u}_{k}\right)}{\left|\nabla G\left(\underline{u}_{k}\right)\right|^{2}}
$$


where $G(\underline{u})=0$ is the limit state function, $\nabla$ the gradient operator and || the length of the vector. For the problems considered here, this procedure does not generally converge towards the design point $\underline{u}^{*}$, defined as the point on $G(\underline{u})=0$ with the shortest distance to origin.

\section{Modified Hasofer-Lind method (M-HL)}

Based on the previous iteration step $\underline{u}_{k}$ the new iteration point $\underline{u}_{k+1}$ is determined from a line search along the line:

$$
\underline{u}=\varsigma \underline{a}_{k}+(1-\varsigma) \underline{u}_{k}
$$

where $\underline{a}_{k}$ is given by Eq. (15). The scalar $\varsigma$ is determined by a simple stepping procedure until the merit function $m(\underline{u})$

$$
m(\underline{u})=\left[\underline{u}-\frac{\nabla G(\underline{u}) \underline{u}}{|\nabla G(\underline{u})|^{2}} \nabla G(\underline{u})\right]^{2}+c[G(\underline{u})]^{2}
$$

attains a minimum value, yielding

$$
\underline{u}_{k+1}=\underline{u}\left\{m_{s}(\underline{u})=\min \right\}
$$

The weight factor $C$ can be taken in a wide range from 10 to 10,000 without changing the convergence significantly. The range investigated for $\varsigma$ is $\varsigma \in] 0,4]$. Convergence is found in all cases considered, but the procedure is somewhat expensive as it requires gradient calculations $\nabla G(\underline{u})$ for all values of $\varsigma$ used in Eq. (16).

\section{Hasofer-Lind with circle and line step extension (HL-CL)}

Based on the previous iteration step $\underline{u}_{k}$ the new iteration point $\underline{u}_{k+1}$ is determined from first a circle search along the circle:

$$
\underline{u}=\frac{\left|\underline{a}_{k}\right|}{\left|\varsigma \underline{a}_{k}+(1-\varsigma) \underline{u}_{k}\right|}\left(\varsigma \underline{a}_{k}+(1-\varsigma) \underline{u}_{k}\right)
$$

where $\underline{\boldsymbol{a}}_{k}$ is given by Eq. (15). The scalar $\varsigma$ is determined by a simple stepping procedure until the limit state function $G(\underline{u})$ attains its minimum value. The corresponding value of $\underline{u}$ is denoted $\underline{\tilde{u}}$. Thereafter a line search along the line:

$$
\underline{u}=\xi \underline{\tilde{u}}
$$

is performed. The scalar $\xi$ is determined such that the limit state function $G(\underline{u})=0$ yielding

$$
\underline{u}_{k+1}=\xi \underline{\tilde{u}}\{\underset{\xi}{G}(\xi \underline{\tilde{u}})=0\}
$$


This value of $\xi$ is determined iteratively by a Newton-Raphson approach. Thus the new guess

$$
\xi_{i+1}=\xi_{i}-\frac{\xi_{i}-\xi_{i-1}}{G\left(\xi_{i} \underline{\tilde{u}}\right)-G\left(\xi_{i-1} \underline{\tilde{u}}\right)} G\left(\xi_{i} \underline{\tilde{u}}\right)
$$

is obtained based on previous values at iteration step $i$ and $i-1$. For the first step, $\xi_{1}=1+G(\tilde{u})$ is used quite arbitrary, but providing a change in the correct direction as $G$ decreases with increasing $\xi$.

The convergence property of this scheme is just as good as for the M-HL procedure but with a large reduction of CPU time. The reason is that gradient calculations are not needed during the circle and line search as opposite to the M-HL method. With a large number of components in $\underline{u}$, say 100 as here, a large reduction, a factor of five, in CPU time is therefore achieved. Both procedures, however, converge for all target angles tested and to the same reliability index. The two procedures have also been tested for the case of parametric rolling, Jensen (2007), and here the M-HL procedure converges for all cases considered whereas the HL-CL failed to converge.

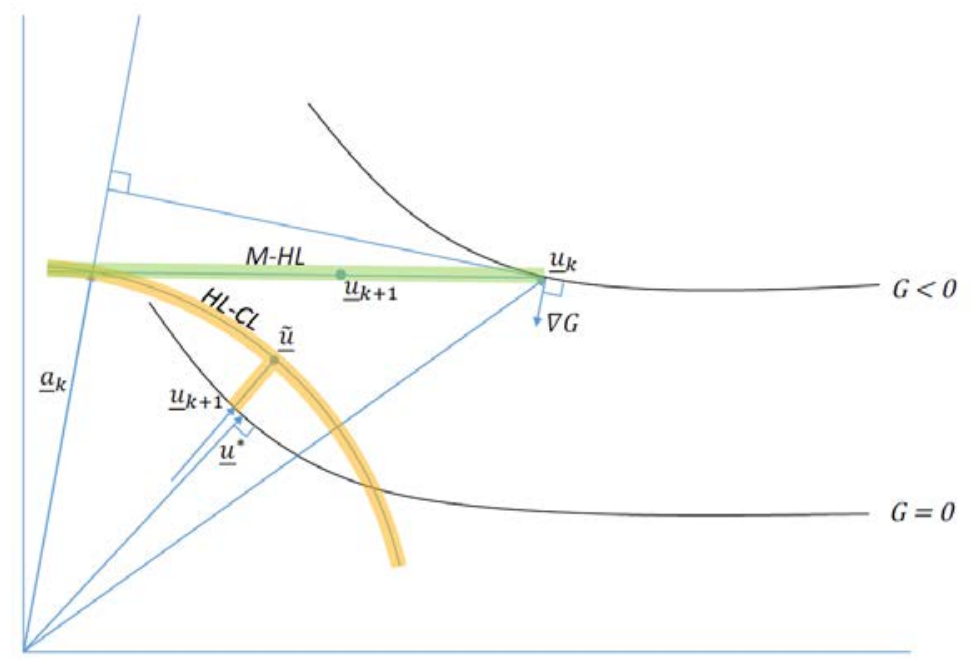

Fig. 19. Search procedures for the M-HL (green) and HL-CL (yellow) methods 